\title{
Simple, expedient methods for the determination of water and electrolyte contents of cellulose solvent systems
}

\author{
Ludmila C. Fidale ${ }^{1}$, Sarah Köhler ${ }^{2}$, Martin H.G. Prechtl ${ }^{3}$, Thomas Heinze ${ }^{2}$ \\ and Omar A. El Seoud ${ }^{1, *}$ \\ ${ }^{1}$ Instituto de Química, Universidade de São Paulo, C.P. 26077, 05513-970, São Paulo, S.P., Brazil; \\ ${ }^{2}$ Kompetenzzentrum für Polysaccharidforschung, Friedrich-Schiller-Universität Jena, Humboldtstraße 10, \\ D-07743, Jena, Germany; ${ }^{3}$ Max-Planck Institut für Kohlenforschung, Kaiser Wilhelm Platz 1, D-45470, \\ Mülheim an der Ruhr, Germany; *Author for correspondence (e-mail: elseoud@iq.usp.br; fax: + 55-11-3091- \\ 3874)
}

Received 1 November 2005; accepted in revised form 3 December 2005

Key words: Dissolution of cellulose, Electrolyte content, FTIR, Ion-selective electrodes, Karl Fischer titration, $\mathrm{LiCl} / N, N$-dimethylacetamide, Solvatochromism, TBAF.x hydrate/dimethyl sulfoxide, Water content

\begin{abstract}
The concentrations of water, $\mathrm{W}$, and electrolytes present in solutions of $\mathrm{LiCl}$ in $N, N$-dimethylacetamide, $\mathrm{LiCl} / \mathrm{DMAc}$, and of tetrabutylammonium fluoride. $\mathrm{x}$-hydrate in DMSO, TBAF.xW/DMSO can be accurately and expediently determined by three independent methods, UV-vis, FTIR and EMF measurement. The first relies on the use of solvatochromic probes whose spectra are sensitive to solution composition. It is applicable to $\mathrm{W} / \mathrm{LiCl} / \mathrm{DMAc}$ solutions but not to TBAF.xW/DMSO, because the charge-transfer complex bands of the probes are suppressed by strong interactions with the latter electrolyte. Integration of $v_{\mathrm{OH}}$ band of water may be employed in order to determine [W], hence [electrolyte] by weight difference. EMF measurement uses ion-selective electrodes in order to determine [electrolyte], hence [W] by weight difference. Results of the latter method were in excellent agreement with those of FTIR. The reason for the failure of Karl Fischer titration is addressed, and the relevance of the results obtained to functionalization of cellulose under homogenous solution conditions is briefly commented on.
\end{abstract}

\section{Introduction}

The impetus for the continued search for solvents that dissolve cellulose is to obtain better-quality products. Thus cellulose and its esters, in particular acetates, with upgraded properties may be obtained by precipitation from their (homogeneous) solutions (Woodings 1995; Chavan and Patra 2004; Heinze and Liebert 2004; Steinmeier 2004). Compared with the industrial, i.e., hetero- geneous functionalization process (Toyoshima 1993), cellulose derivatization under homogeneous reaction conditions offers a distinct advantage because products of any degree of substitution (in the anhydrous glucose unit) may be directly obtained from the native polymer, with minimum degradation (Heinze and Liebert 2001; El Seoud and Heinze 2005). The solvent system most extensively studied is lithium chloride in $N, N$ dimethylacetamide, LiCl/DMAc (Dawsey and 
McCormick 1990; Samaranayake and Glasser 1993; El Seoud et al. 2000; Dupont 2003; El Seoud and Heinze 2005; Ramos et al. 2005). More recently, tetra-n-butylammonium fluoride hydrate in dimethylsufoxide, TBAF.xW/DMSO has been successfully employed for cellulose dissolution/ functionalization (Heinze et al. 1999, 2000, 2003; Ass et al. 2004). Here we employ (W) to denote water and $(\mathrm{xW})$ to denote the water of hydration of TBAF, presumably trihydrate. The term 'solvent system' designates an electrolyte solution in a polar aprotic solvent. It is intended to differentiate these systems from room-temperature ionic liquids, where cellulose dissolution does not require an (additional) electrolyte. The interactions of the ionic liquid with the hydroxyl groups of the polymer are probably strong enough to disrupt hydrogen-bonding, leading to polymer dissolution (Swatloski et al. 2002; Spear et al. 2004; Wu et al. 2004; Turner et al. 2004; Heinze et al. 2005). The much higher cost of ionic liquids, relative to the above-mentioned solvent systems means that the latter will continue to generate much interest, e.g., for obtaining specialty products, including water-absorbing fibers and hemodialysis membranes (Diamantoglou et al. 1984; Diamantoglou and Vienken 1996; Lacey 1997; Abe and Mochizuki 2003). Production of these derivatives rests on optimization, leading to cost reduction, of the three steps involved, namely, cellulose activation, dissolution and functionalization. With these objectives in mind, we decided to investigate simple, expedient methods for the determination of the water and electrolyte concentrations of the above-mentioned solvent systems. Note that this objective, if achieved, should lead to economy of energy/labor, and a better control of cellulose derivatization. The electrolytes employed, in particular TBAF.xW, are very hygroscopic, their drying is time- and energy-consuming. As has been demonstrated elsewhere, TBAF.xW cannot be dried by heating because it undergoes Hofmann elimination reaction (Sharma and Fry 1983). An alternative approach is to employ partially dried electrolyte, but the medium composition, in terms of [electrolyte] and [W], should be known accurately. This knowledge is important for several reasons: (i) the presence of unknown concentrations of (adventitious) water may lead to conflicting results as shown, e.g., by the (inconsistent) solubility limits reported for $\mathrm{LiCl}$ in 'anhydrous'
DMAc (Potthast et al. 2002); (ii) the complex role played by water warrants a careful determination of its concentration. For example, its presence affects the aggregation state of dissolved cellulose, hence its reactivity (Terbojevich et al. 1995; Sjoholm et al. 1997; Potthast et al. 2002; El Seoud and Heinze 2005). As discussed elsewhere for cellulose esterification in TBAF.xW/DMSO, the amount of residual water should be carefully controlled, so that its (beneficial) effect on cellulose dissolution is not canceled out by its (deleterious) effect on reaction yield, due to a combination of consumption of the acylating agent and hydrolysis of the ester produced (Ass et al. 2004).

We show that Karl Fischer titration is not convenient for the determination of water in these solvent systems. On the other hand, solvatochromic indicators may be conveniently employed, but only for $\mathrm{LiCl} / \mathrm{DMAc}$. Both FTIR and ion-selective electrodes, ISEs, are recommended because they are simple, expedient and give consistent results.

\section{Experimental}

\section{Solvents and reagents}

These were purchased from Merck or Acros, and were employed as received, or treated as follows: DMAc and DMSO, distillation from $\mathrm{CaH}_{2} ; \mathrm{LiCl}$, drying at $200{ }^{\circ} \mathrm{C}$ for $4 \mathrm{~h} ; \mathrm{C}_{6} \mathrm{~F}_{6}$, agitation at room temperature with $5 \%$ sulfuric acid, followed by washing with water and drying (Armarego and Chai 2003). TBAF.xW was either commercial, or was prepared by the reaction of equi-molar amounts of aqueous $\mathrm{HF}$ and $\left(\mathrm{n}-\mathrm{C}_{4} \mathrm{H}_{9}\right)_{4} \mathrm{~N}^{+} \mathrm{OH}^{-}$solutions. A waxy white solid was obtained after lyophilization of the solution, followed by further drying at room temperature, under reduced pressure, over $\mathrm{P}_{4} \mathrm{O}_{10}$. Anhydrous TBAF in DMSO was obtained by reacting $\left(\mathrm{n}-\mathrm{C}_{4} \mathrm{H}_{9}\right)_{4} \mathrm{~N}^{+} \mathrm{CN}^{-}(6.31 \mathrm{mmol})$ with $\mathrm{C}_{6} \mathrm{~F}_{6}$ $(1.047 \mathrm{mmol})$ in $50 \mathrm{ml}$ anhydrous DMSO for $1 \mathrm{~h}$ (Sun and DiMagno 2005).

The solvatochromic indicators employed were 2,6-diphenyl-4-(2,4,6-triphenylpyridinium-1-yl) phenolate (RB, commercial) and 2,6-dichloro-4(2,4,6-triphenyl pyridinium-1-yl) phenolate (WB, synthesized as reported elsewhere (Kessler and Wolfbeis 1989; Tada et al. 2000), see structures in Figure 1. 
<smiles>[O-]c1c(-c2ccccc2)cc(-[n+]2cc(-c3ccccc3)cc(-c3ccccc3)[n+]2-c2ccccc2)cc1-c1ccccc1</smiles>

$\mathrm{RB}$<smiles>[2H]c1c(Cl)c([O-])c(Cl)c([O-])c1-[n+]1c(-c2ccccc2)c([2H])c(-c2c(C)cccc2C)c([2H])c1-c1ccccc1</smiles>

WB

Figure 1. Structures of the solvatochromic probes employed. The hydrogens of WB are designated because of the ${ }^{1} \mathrm{H}-\mathrm{NMR}$ experiment, vide infra.

Determination of water and electrolyte contents of $\mathrm{LiCl} / \mathrm{DMAc}$ and TBAF.xW/DMSO

All glassware was carefully dried after being assembled. Transfers of all solvents and/or electrolyte solutions has been carried out under dry nitrogen by employing rubber septa and cannulas, as recommended elsewhere for air/moisture-sensitive liquids (Casey et al. 1990).

Direct determination of [water] by Karl Fischer titration. This has been carried out according to the standard procedure (Scholz 1984), by using Schott 1200 Titration controller, equipped with T200 automatic burette, TZ1745 titration vessel, TM125 magnetic stirrer and PT1400 electrode.

Direct determination of [water] by using solvatochromic indicators. A solution of the polarity indicator in the solvent employed was added to the electrolyte solution in the same solvent, so that the final probe concentration was $1-5 \times 10^{-4} \mathrm{~mol} / \mathrm{l}$. The UV-vis spectra of the resulting solutions were recorded at $25 \pm 0.1{ }^{\circ} \mathrm{C}$, as a function of time, by using Beckman DU-70 UV-vis spectrometer, provided with a thermostated cell-holder. Values of $\lambda_{\max }$ were determined from the first derivative of the spectra. These wavelengths were then employed to calculate the solvent polarity parameter, $E_{\mathrm{T}}$, vide infra.

Direct determination of [water] by FTIR. IR spectra were recorded with Bruker Vector 22 (São Paulo) or Nicolet Avatar 370 (Jena) FTIR spectrometers, whose sample compartments were continuously flushed with dry nitrogen. The number of spectra added and digital resolution were: 32 at $1 \mathrm{~cm}^{-1}$ (Vector 22) or 64 at $4 \mathrm{~cm}^{-1}$ (Avatar 370). Sealed solution cells with $\mathrm{CaF}_{2}$ windows and $0.025 \mathrm{~mm}$ path-length were employed. The background spectra were: air, for measuring [W] in DMAc or DMSO; pure solvent, for measuring [W] in the solvent system. The peakareas of the $v_{\mathrm{OH}}$ bands (taken between 3100 and $3700 \mathrm{~cm}^{-1}$ ) were calculated with the aid of commercial software, GRAMS/32 program package (Galactic Industries) or Omnic version 7.0 (Nicolet). Baseline correction and smoothing were applied to the peaks.

Direct determination of [electrolyte] by chloride and fluoride ISEs. Fisher Accumet-50 ion-meter was employed, along with Corning double-junction $\mathrm{Ag} / \mathrm{AgCl}$ reference electrode and the appropriate ISE; Orion 9417BM (chloride) and Orion 940900 (fluoride). All measurements were carried out at $25 \pm 0.1{ }^{\circ} \mathrm{C}$. The following reference solutions were employed for the construction of Nernst plots (i.e., potentials measured versus ln [halide ion]): $5 \times 10^{-4}$ to $2 \times 10^{-2} \mathrm{~mol} / 1 \mathrm{KCl}$ in $0.5 \mathrm{~mol} / 1$ $\mathrm{KNO}_{3} ; 5.3 \times 10^{-5}$ to $1.1 \times 10^{-2} \mathrm{~mol} / 1 \mathrm{NaF}$ in $0.5 \mathrm{~mol} / 1 \quad \mathrm{KNO}_{3}$. The supporting electrolyte, $\mathrm{KNO}_{3}$, was employed in order to suppress any effect of the change of $\mathrm{KCl}$ or $\mathrm{NaF}$ on the potential measured by the ISE (Liptak 1994; Mussini et al. 1985). The 'water' employed for making-up these 
reference solutions contained $0.5 \%$ DMAc or $0.5 \%$ DMSO $(\mathrm{v} / \mathrm{v})$. Aliquots of $\mathrm{LiCl} / \mathrm{DMAc}$ or TBAF.xW/DMSO were diluted with water so that the final solution contained the same volume percentage of the organic co-solvent. The halide ion concentration (hence electrolyte concentration) was calculated from the potential measured and the appropriate Nernst law plot. The water contents of $\mathrm{LiCl} / \mathrm{DMAc}$ or TBAF/DMSO were calculated from the difference between weights of the starting (partially hydrated) electrolytes and those calculated from Nernst law plot.

\section{Kinetics of water absorption by electrolyte solutions}

The rate constants for water uptake by electrolyte solutions were determined at $24 \pm 1{ }^{\circ} \mathrm{C}$ and $59 \pm 1 \%$ relative humidity. All experiments were carried out in duplicates. $\mathrm{LiCl}$ and TBAF.xW were dissolved in DMAc and DMSO, respectively, the resulting solutions $(15 \mathrm{ml}, 1.0$ and $0.5 \mathrm{~mol} / 1$, respectively) were transferred to Petri dishes $(9 \mathrm{~cm}$ diameter), the latter brought into contact with the controlled temperature/humidity atmosphere, and weighted periodically, for $6 \mathrm{~h}$. Pseudo first-order rate constants, $k_{\text {obs }}$, were calculated from nonlinear least-squares analysis of plots of $\log$ $\left[(\text { weight })_{\infty}-(\text { weight })_{t}\right]$ versus time, where $(\infty)$ and $(t)$ refer to the weight of the sample at 'infinity' time (calculated by iteration) and that at time $(t)$, respectively. These plots were linear up to two half-lives. The uncertainties in the observed rate constants, $k_{\text {obs }}$, were $\leq 2 \%$.

\section{Results and discussion}

Quantifying the hygroscopic nature of electrolyte solutions

The hygroscopic nature of the electrolyte solutions can be quantified from kinetic data, see Figure 2. Our results showed that water absorption obeyed pseudo first-order kinetics, whose $k_{\text {obs }}$ were found to be 4.2 and $3.4 \times 10^{-5} \mathrm{~s}^{-1}$, for $1.0 \mathrm{~mol} / 1 \mathrm{LiCl} /$ DMAc and $0.5 \mathrm{~mol} / 1 \mathrm{TBAF} . \mathrm{xW} / \mathrm{DMSO}$, respectively. Dividing $k_{\text {obs }}$ by [electrolyte] gives the following second-order rate constants, respectively: 4.2 and $6.8 \times 10^{-5} \mathrm{M}^{-1} \mathrm{~s}^{-1}$, i.e., TBAF. $\mathrm{xW} /$ $\mathrm{DMSO}$ is more hygroscopic than $\mathrm{LiCl} / \mathrm{DMAc}$.

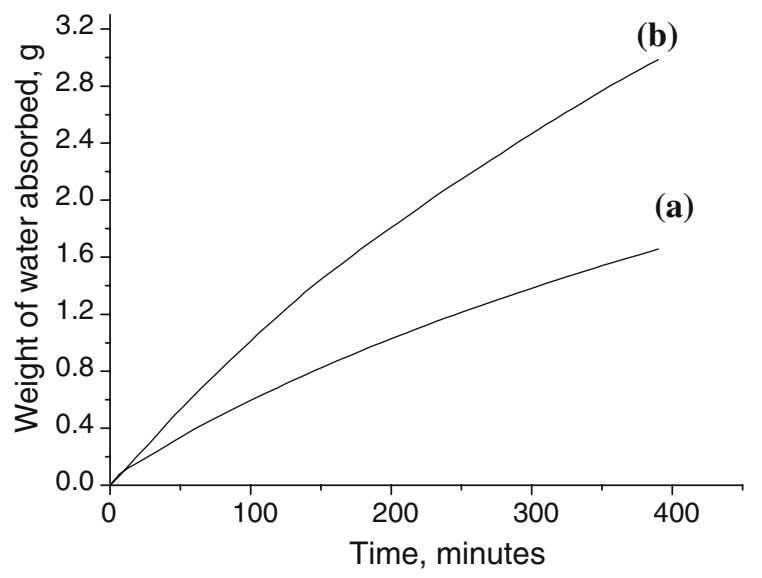

Figure 2. Time-dependence of water uptake by electrolyte solutions. The plots are for $1.0 \mathrm{~mol} / 1 \mathrm{LiCl} / \mathrm{DMAc}$ (a), and $0.5 \mathrm{~mol} / 1 \mathrm{TBAF} . \mathrm{xW} / \mathrm{DMSO}$ (b), respectively.

Water absorption by $\mathrm{LiCl} / \mathrm{DMAc}$ agrees with the (qualitative) observation previously made (Potthast et al. 2002), and underlines the need to avoid exposure to air during all steps of cellulose derivatization.

\section{Use of Karl Fischer titration for water determination}

This method is perhaps the most extensively employed procedure for the determination of water content in a myriad of substances (Kolthoff and Elving 1971; Scholz 1984). We examined its application to $2 \%$ TBAF.xW/DMSO solutions. Known amounts of water were added, to give $[\mathrm{W}]_{\text {added }}=0.23$ to $1.19 \mathrm{~mol} / 1$ and the (six) solutions were titrated. The slope of Eq. (1) shows that the water concentrations calculated, $[\mathrm{W}]_{\text {calculated, }}$, were much smaller than those added:

$$
\begin{gathered}
{[\mathrm{W}]_{\text {calculated }}=0.220+0.275[\text { Water }]_{\text {added }},} \\
\text { correlation coefficient, } \quad r=0.974
\end{gathered}
$$

This may be traced to the fact that most of the water present is tightly-bound to TBAF, being inaccessible to Karl Fischer reagent (Aichert et al. 1998; De Caro et al. 2001). A measure of this tightness is given by the enthalpies of hydration, -464.8 and $-303.8 \mathrm{~kJ} / \mathrm{mol}$, for $\mathrm{LiCl}$ and TBAF, respectively (Marcus 1997). Other problems with this method include: (i) The slope of the above-shown correlation is electrolyte concentration-dependent, being 0.183 in the presence 
of $3 \%$ TBAF.xW/DMSO. This is problematic because a calibration curve should be constructed for each electrolyte concentration employed! (ii) Other modifications in the method, employed in order to solve the water accessibility problem are not applicable to the present case. E.g., quantitative removal of tightly bound water by gradually heating the solution to high temperatures $\left(250^{\circ} \mathrm{C}\right.$ for liquid crystalline amphiphiles, Dunkel et al. 1998) is inappropriate because of Hofmann degradation of TBAF at much lower temperatures, e.g., $77{ }^{\circ} \mathrm{C}$ at $2 \mathrm{mmHg}$ (Sharma and Fry 1983). The conclusion that Karl Fischer titration is unsuitable for the quantitative determination of water in TBAF.xW/DMSO solutions agrees with that drawn for the $\mathrm{LiCl} / \mathrm{DMAc}$ counterpart (Potthast et al. 2002).

\section{Use of Solvatochromic probes}

\section{Principle of the method}

The water content of a binary mixture may be determined by using solvatochromic probes. These are compounds whose spectra, absorption or emission are sensitive to the polarity of the medium, hence to its composition. Extensive use has been made of an empirical solvent polarity scale, $E_{\mathrm{T}}$, calculated by Eq. (2) (Reichardt 2003):

$$
E_{\mathrm{T}}(\mathrm{kcal} / \mathrm{mol})=28591.5 / \lambda_{\max }(\mathrm{nm})
$$

This scale converts the electronic transition within the probe into the corresponding intra-molecular transition energy in $\mathrm{kcal} / \mathrm{mol}$. This allows the determination of binary solvent composition from plots of $E_{\mathrm{T}}$ (probe) versus [W]. The solvent polarity scales of the probes depicted in Figure 1 are referred to as $E_{\mathrm{T}}(30)$ and $E_{\mathrm{T}}(33)$, respectively. Because of preferential solvation of the probe by one component of the binary mixture, the relationship between $E_{\mathrm{T}}$ (probe) and solvent composition is usually complex (Tada et al. 2000, 2003, 2005). For instance, in W/DMSO mixtures, $E_{\mathrm{T}}(33)$ is related to the mole fraction of water, $\chi_{\mathrm{W}}$ by Tada (2004):

$$
\begin{aligned}
E_{\mathrm{T}}(33)= & 54.34+8.14\left(\chi_{\mathrm{W}}\right)+23.68\left(\chi_{\mathrm{W}}\right)^{2} \\
& -45.21\left(\chi_{\mathrm{W}}\right)^{3}+29.31\left(\chi_{\mathrm{W}}\right)^{4}, \quad r^{2}=0.999
\end{aligned}
$$

Over a smaller $\chi_{\mathrm{w}}$ range, however, the polarity versus composition relationship may be described by a lower-power polynomial, or may even be a straight line (Langhals 1982).

RB has been successively employed for the determination of [W] in DMAc. A (neutral) fluorescent probe was used for the determination of [W] in $\mathrm{LiCl} / \mathrm{DMAc}$, because the high ionic strength of the solution 'inevitably causes aggregation of chromophore molecules resulting in a change of the UV absorption' (Potthast et al. 2002). We decided to examine the suitability of RB and $\mathrm{WB}$ for water determination in $\mathrm{LiCl} / \mathrm{DMAc}$ and TBAF.xW/DMSO. The reason is that the solvatochromic behavior of fluorescent probes is much less studied, and understood, than that of (UV-vis absorbing) zwitterionic probes (Reichardt 2003).

\section{Choice of the indicators}

A comment concerning the choice of RB and WB as solvatochromic probes is in order. The former is probably the most extensively studied probe, both in pure solvents and in binary solvent mixtures. We decided to include the structurally similar WB because of the following reasons: (i) The presence of two ortho chlorine atoms in the phenolate moiety of WB make it much less basic than RB, $\mathrm{pKa}$ in water $=4.78$ and 8.65 , respectively (Tada et al. 2000). This lower basicity is advantageous because no solvatochromism is observed if the probe is protonated, e.g., by traces of (spurious) acidic impurities present in the solution; (ii) The lower basicity of WB does not decrease its hydrogen-bonding ability, relative to that of RB. Briefly, this is due to two factors: The formation of hydrogen-bonds to the phenolate ion of $\mathrm{RB}$ is attenuated because of the steric crowding by the two ortho phenyl groups; The $\mathrm{C}^{\delta+}-\mathrm{Cl}^{\delta-}$ dipoles of $\mathrm{WB}$ are sites for additional hydrogen-bonding (Tada et al. 2000). That is, the dependence of $E_{\mathrm{T}}$ (probe) on [W] (hence the accuracy of the determination) is not expected to be different for both indicators; (iii) WB is less hydrophobic than $\mathrm{RB}$ and, therefore, is less likely to auto-aggregate in the solution.

\section{Solvatochromic behavior in pure solvents and in solutions of $\mathrm{LiCl}$}

Beer's law applies to both indicators in dry DMAc or DMSO, in the [probe] range of $1-5 \times$ $10^{-4} \mathrm{~mol} / \mathrm{l}$, i.e., there is no probe auto-association. We have found that WB may be employed for 
determination of water in DMSO; the corresponding polynomial for the dependence of $E_{\mathrm{T}}(\mathrm{WB})$ on $[\mathrm{W}]$ is:

$$
\begin{aligned}
E_{\mathrm{T}}(\mathrm{WB})= & 54.244( \pm 0.041)+0.718( \pm 0.026)[\mathrm{W}] \\
& -0.026( \pm 0.003)[\mathrm{W}]^{2} ; \quad r^{2}=0.9987
\end{aligned}
$$

Therefore, both RB and WB may be employed for accurate water determination in DMAc and DMSO.

Next, we examined the effect of electrolytes, whose presence may lead to halo-solvatochromism. This phenomenon results from changes in the energetics of the probe intra-molecular charge transfer complex, CTC, due to its association with the electrolyte. Its occurrence may lead to blue shift of the CTC band and variation in absorbance (Reichardt 2003). We found that Beer's law applies to WB $\left(1-5 \times 10^{-4} \mathrm{~mol} / \mathrm{l}\right)$ in the presence of $1.0 \mathrm{~mol} / 1 \mathrm{LiCl} / \mathrm{DMAc}$ and/or $1.0 \mathrm{~mol} / 1 \mathrm{LiCl} /$ DMSO. Therefore, there is no detectable autoassociation of this probe at relatively high [ $\mathrm{LiCl}]$, i.e., it may be employed for the determination of water in electrolyte solutions. Halo-solvatohromism, however, was observed, e.g., the values of $\lambda_{\max }$ were $528,526,512$ and $471 \mathrm{~nm}$ for $\mathrm{WB}$ in DMSO, and in $0.01,0.1$ and $1.0 \mathrm{~mol} / 1 \mathrm{LiCl} /$ DMSO, respectively.

On the other hand, the CTC-band of RB disappeared completely in the presence of 0.5 and $1.0 \mathrm{~mol} / 1 \mathrm{LiCl}$ in DMSO. This is not due to dye protonation by (spurious) traces of an acidic impurity because the same behavior was observed when the ( $\mathrm{LiCl} / \mathrm{DMSO}$ ) solution was previously stirred with solid $\mathrm{K}_{2} \mathrm{CO}_{3}$. The CTC bands of $\mathrm{RB}$ were observed, however, in the presence of lower [LiCl], 0.01 and $0.1 \mathrm{~mol} / 1$, respectively. The latter result is easily explained because strong electrolyte-probe interactions may result in complete suppression of the CTC band; the concentration of free probe depends on the total electrolyte concentration. That is, RB may also be employed for the determination of [W], although at much lower [LiCl] $\leq 0.1 \mathrm{~mol} / 1$ or $0.42 \%$. This use is of little value since cellulose dissolution occurs at much higher electrolyte concentrations (El Seoud and Heinze 2005).

In the next set of experiments, we employed WB for the determination of [W], in the range $0.05-$ $4.0 \mathrm{~mol} / 1$, in presence of $1.0 \mathrm{~mol} / 1$ of $\mathrm{LiCl}$. The following equations were calculated from the absorbance data:

$$
\begin{aligned}
E_{\mathrm{T}}(33)_{\mathrm{DMAc}}= & 61.04( \pm 0.03) \\
& -0.30( \pm 0.01)[\mathrm{W}], \quad r=0.9945
\end{aligned}
$$

$$
\begin{aligned}
E_{\mathrm{T}}(33)_{\mathrm{DMSO}}= & 60.49( \pm 0.01) \\
& -0.16( \pm 0.01)[\mathrm{W}], \quad r=0.9995
\end{aligned}
$$

The slopes are negative because the polarity of the probe microenvironment (WB...LiCl...W) probably decreases as a function of increasing [W], due to progressive hydration of the electrolyte. Interestingly, the $\mid$ slope $\mid$ in DMSO is smaller than that in DMAc, in agreement with the fact that the basicity of the former solvent (hence the strength of its interaction with water) is larger than that of the latter. A measure of solvent basicity is its (solvatochromic-based parameter) $\beta, 0.69$ and 0.76 for DMAc and DMSO, respectively (Reichardt 2003).

\section{Solvatochromic behavior TBAF.xW/DMSO solutions}

Before use, all solutions of TBAF.xW/DMSO were stirred with solid $\mathrm{K}_{2} \mathrm{CO}_{3}$ then filtered. That is, any change in the CTC band, if it occurs, is not due to probe protonation by an acidic impurity. The conditions employed were: [probe] $=1.8 \times 10^{-4}$ mol/1, [TBAF.xW] $0.025,0.05,0.1$ and $0.25 \mathrm{~mol} / 1$. Addition of any of these electrolyte solutions to WB resulted in the disappearance of the CTC band, and the appearance of another one whose intensity at $422 \mathrm{~nm}$ was found to be time-independent, see Figure 3. A similar behavior was observed for RB/ TBAF.xW/DMSO, although the absorbance at ca. $420 \mathrm{~nm}$ was found to be time-dependent (Figure 3).

For $\mathrm{WB}, E_{\mathrm{T}}(33)$ at $422 \mathrm{~nm}$ corresponds to $67.8 \mathrm{kcal} / \mathrm{mol}$, a value that is higher than that of typical protic solvents, e.g., alcohols, ethylene glycol and glycerol, and is only slightly smaller than that of water $(70.2 \mathrm{kcal} / \mathrm{mol})$. This high polarity is inconsistent with the fact that the solution is relatively dry, i.e., the peak observed is not the CTC-band. The same line of reasoning applies to the corresponding results of $\mathrm{RB}$.

Because water affects dye-electrolyte interactions, hence halo-solvatochromism, both indicators were tested for the determination of 
[W], $0.5-4.0 \mathrm{~mol} / 1$, in the presence of $0.25 \mathrm{~mol} /$ 1 of TBAF.xW/DMSO. Addition of the electrolyte solution to the dye resulted in timedependent color changes, from purple to dark yellow (WB), and from green to dark yellow (RB), see Figure 4. The rate of color change was found to be inversely dependent on [W]; is faster for WB than for RB, at the same [W]. As argued above, the steric crowding in the phenolate moiety of RB decreases its interactions with Lewis acids, the tetrabutylammonium ion in the present case.

After $6 \mathrm{~h}$, the only peaks observed for both indicators were at ca. 415 and $410 \mathrm{~nm}$, corresponding to $E_{\mathrm{T}}$ of 68.9 and $69.7 \mathrm{kcal} / \mathrm{mol}$, for WB and $\mathrm{RB}$, respectively. These bands are not CTC ones, since $E_{\mathrm{T}}$ (probe) calculated are larger than the values of pure water, 55.1 and $63.1 \mathrm{kcal} / \mathrm{mol}$, for $\mathrm{WB}$ and $\mathrm{RB}$, respectively. Therefore, strong probe-electrolyte interactions suppress the CTCbands in absence and presence of water. This turns both probes insensitive to solvent composition, i.e., unsuitable for our purpose.

The previous conclusion is corroborated by examining the ${ }^{1} \mathrm{H}-\mathrm{NMR}$ spectra of $\mathrm{WB}$ in the absence and presence of TBAF.xW/DMSO- $\mathrm{d}_{6}$ (final concentrations $=10 \mathrm{mg} \mathrm{WB}$ and $10 \mathrm{mg}$ electrolyte $/ 0.5 \mathrm{ml}$ solvent). After $24 \mathrm{~h}$ of mixing, the only differences observed in the spectra were the up-field shifts of the dye protons, with $\Delta \delta=\delta_{\text {after mixing }}-\delta_{\text {after } 24 \mathrm{~h}}=2.7, \quad 0.3, \quad 1.8$ and
$3.6 \mathrm{~Hz}$, for protons $\mathrm{a}, \mathrm{b}, \mathrm{c}$ and $\mathrm{d}$, respectively (see Figure 1 for designation of the protons of WB). This order reflects a stronger interaction between $\mathrm{F}^{-}$and the positively-charged heterocyclic nitrogen, and a much weaker interaction of $\left(\mathrm{n}-\mathrm{C}_{4} \mathrm{H}_{9}\right)_{4} \mathrm{~N}^{+}$with the phenolate anion, due to the above-mentioned steric hindrance.

The difference between the solvatochromic behavior in the presence of $\mathrm{LiCl}$ and TBAF can be readily explained, based on the strength of the probe-electrolyte interactions, being inversely proportional to the strength of the association of the electrolyte ions. Because of the large difference between the sizes and charge densities of the $\mathrm{Li}^{+}$ and $\left(\mathrm{n}-\mathrm{C}_{4} \mathrm{H}_{9}\right)_{4} \mathrm{~N}^{+}$cations, $\mathrm{LiCl}$ is more associated than TBAF.xW in dipolar aprotic solvents. This may be inferred from: (i) In typical dipolar aprotic solvents, acetone, acetronitrile and DMSO, the solubility of tetraalkylammonium halides is higher than those of the corresponding alkali metal halides (Nakayama 1983; Wynn et al. 1984; Levkin and Tsivadze 1986; Abakshin et al. 1987; Sipos et al. 1997; Ikeda et al. 2003; Ass et al. 2004); (ii) The free energies of transfer from water to acetonitrile are more favorable for TBAF $(39 \mathrm{~kJ} / \mathrm{mol})$ than for $\mathrm{LiCl}(66 \mathrm{~kJ} / \mathrm{mol})$ (Marcus 1997). The interaction of $\mathrm{LiCl}$ with the probe is, therefore, weaker than that of TBAF, leading to halo-solvatochromism, without affecting the CTC-band. On the other hand, the weak association of the ions of TBAF combined with the small size and hardness
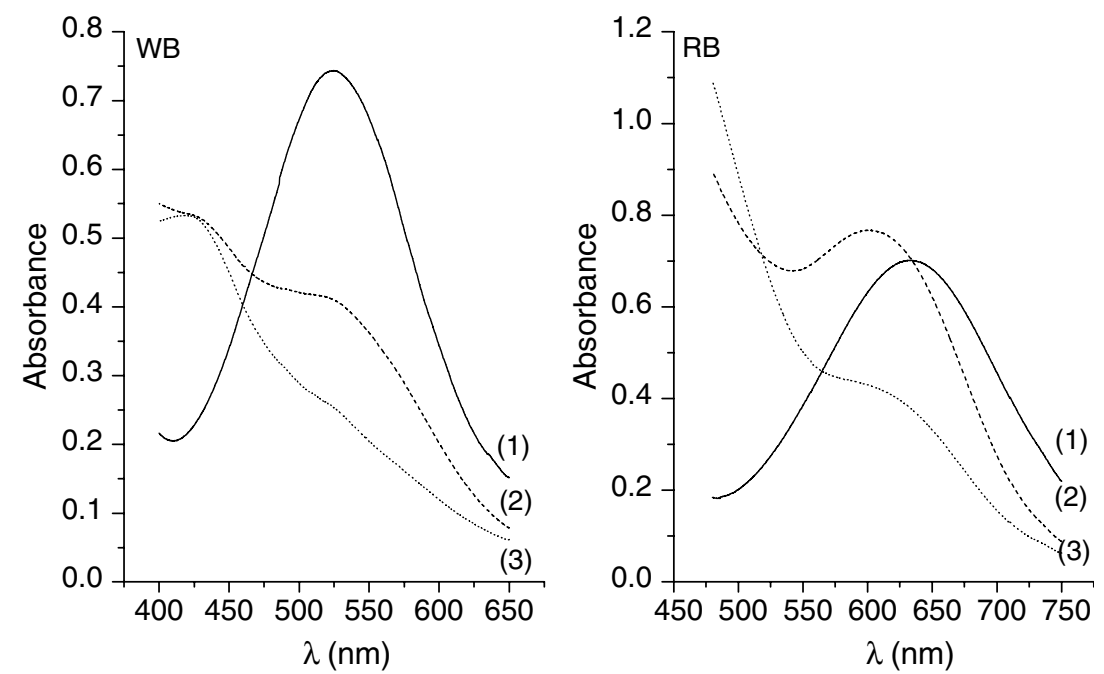

Figure 3. Effects of TBAF.xW on the UV-vis spectra of WB and RB. In both cases, the curves were recorded for the probe in DMSO (curve 1) and in the presence of $0.025 \mathrm{~mol} / 1 \mathrm{TBAF} . \mathrm{W} / \mathrm{DMSO}$, after 5 (curve 2) and 25 min (curve 3), respectively. 

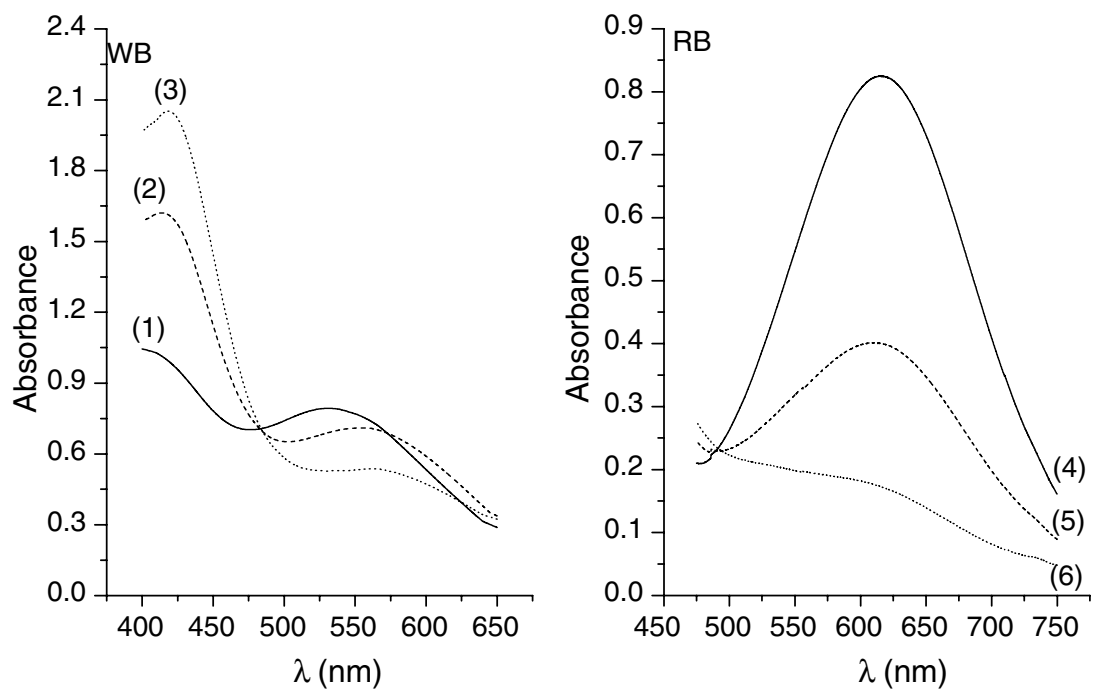

Figure 4. Time dependence of the UV-vis spectra of WB and RB in the presence of $0.25 \mathrm{~mol} / 1 \mathrm{TBAF}$. W/DMSO and [W] $=2.5 \mathrm{~mol} / 1$. For WB the spectra were recorded after 5, 30 and 60 min, curves (1), (2) and (3), respectively. For RB, the corresponding curves were recorded after 5, 60 and $180 \mathrm{~min}$, curves (4), (5) and (6), respectively.

of the $\mathrm{F}^{-}$(the hardest base known) (Pearson 1988) leads to a strong probe-electrolyte association, and suppression of the solvatochromic CTC band.

In summary, the probes studied may be employed for the accurate determination of [W] in some solvent systems that are employed for cellulose dissolution. Halo-solvatochromism is not problematic, provided that the electrolyte-probe association is not strong enough to suppress the CTC-band. An alternative approach is to use a (neutral) fluorescent probe; this use, however, has not been tested with TBAF.xW/DMSO (Potthast et al. 2002).

\section{Direct determination of [water] by FTIR}

The $v_{\mathrm{OH}}$ band of water is broad, asymmetric, and possibly contains contributions from coupled water molecule vibrations, and a bending overtone (Mundy et al. 1973; Scherer 1980; Tiddy 1980; WiafeAkenten and Bansil 1983). Although curve fitting of this peak is feasible, attribution of the (typically three) peaks obtained is complex. A safer approach, therefore, is to use the total peak area for determination of [W]. Because of the relatively high [W] investigated, we employed cells with $\mathrm{ZnS}$ windows. It was not possible, however, to measure the peak areas accurately, especially at lower [W], because 'fringes' were found to be superimposed on the base line. These are identical to the interference fringes of the empty cell, and are mostly certainly due to the relatively large difference between the refractive indices of $\mathrm{ZnS}$ (2.4491) and that of the solution (1.4522) (Coleman 1993; Röder et al. 2001). Use of a different window material, with much lower refractive index $\left(\mathrm{CaF}_{2}, 1.3942\right)$ solved this problem.

Figure 5 shows the dependence of peak areas on [W] in DMSO, and on [W] $/ 0.5 \mathrm{~mol} / 1 \mathrm{TBAF} /$ DMSO, whereas Figure 6 shows Beer's law plots for $\mathrm{W} / \mathrm{DMAc}$ and $\mathrm{W} / 1.0 \mathrm{~mol} / 1 \mathrm{LiCl} / \mathrm{DMAc}$. From the latter plots, the following equations for the dependence of $v_{\mathrm{OH}}$ peak area on [W] were calculated:

$$
\begin{gathered}
\text { W/DMAc: Area } v_{\mathrm{OH}}=1.14( \pm 0.85) \\
+64.44( \pm 2.10)[\mathrm{W}], \quad r=0.9974
\end{gathered}
$$

$$
\begin{gathered}
\text { W/DMSO: Area } v_{\mathrm{OH}}=0.94( \pm 0.39) \\
+60.39( \pm 2.13)[\mathrm{W}], \quad r=0.9953
\end{gathered}
$$

$$
\begin{aligned}
& \mathrm{W} / 1.0 \mathrm{~mol} / 1 \mathrm{LiCl} / \mathrm{DMAc} \text { : Area } v_{\mathrm{OH}} \\
& =1.29( \pm 0.41)+43.53( \pm 1.12), \quad r=0.9984
\end{aligned}
$$

$$
\begin{aligned}
& \mathrm{W} / 0.5 \mathrm{~mol} / 1 \mathrm{TBAF} / \mathrm{DMSO}: \text { Area } v_{\mathrm{OH}}=2.96 \\
& ( \pm 0.92)+37.55( \pm 2.12)[\mathrm{W}], \quad r=0.9966
\end{aligned}
$$

The slopes are smaller for water/electrolyte/solvent than for water/solvent. This difference may be 
due to hydration of the electrolyte which affects the $v_{\mathrm{OH}}$ peak shape and width at half-height, hence the peak area calculated (James et al. 1978; Motojima et al. 1981; Lindgren and Kersti 1993; Max and Chapados 2001). Thus FTIR may be employed for the quantitative determination of [W] in these solvent systems. For this and the solvatochromic probe method, the concentration of the electrolyte may be calculated from the difference between the weights of the starting (partially hydrated) electrolyte and that of water.

Direct determination of [electrolyte] by ISE and validation of the methods

Employing an independent technique, e.g., EMF measurements validates the previous results. Rather than 'calibrating' the ion-meter to read a given potential at a certain halide ion concentration as suggested elsewhere (Mussini et al. 1985; Liptak 1994) we have constructed Nernst plots (Figure 7) without prior calibration and obtained the following equations by regression analysis:

$$
\begin{aligned}
& \mathrm{Cl}^{-}: \text {Potential measured, } \mathrm{mV} \\
& \quad=-153.3( \pm 1.1)-25.1( \pm 0.2) \ln \left[\mathrm{Cl}^{-}\right], \quad r=0.9998
\end{aligned}
$$

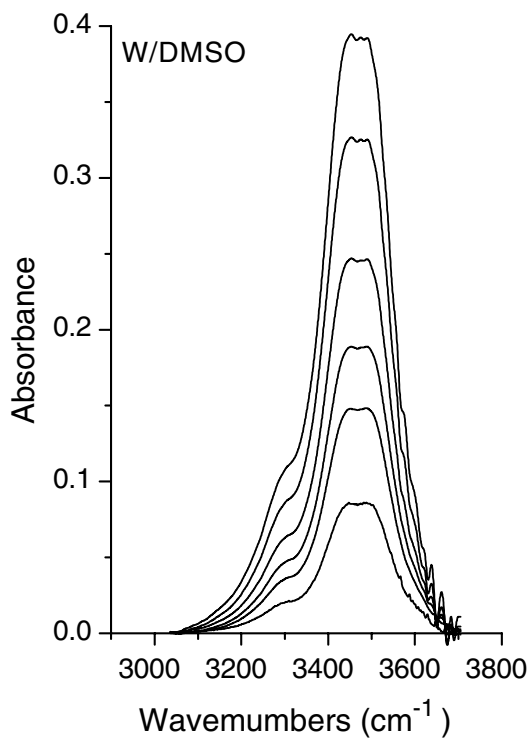

$$
\begin{aligned}
& \mathrm{F}^{-} \text {: Potential measured, } \mathrm{mV}=-332.8( \pm 0.7) \\
& \quad-25.4( \pm 0.1) \ln \left[\mathrm{F}^{-}\right], \quad r=0.9999
\end{aligned}
$$

Next, these plots were employed to calculate [electrolyte] in solutions of $\mathrm{LiCl} / \mathrm{DMAc}$ and TBAF.xW/DMSO, respectively, hence $[\mathrm{W}]$ by weight difference.

The validation has been verified for $\mathrm{LiCl} / \mathrm{DMAc}$ because this solution can be easily obtained anhydrous. [W] of the same stock solution (containing $1.0 \mathrm{~mol} / 1 \mathrm{LiCl}$ ) was calculated from data of the two techniques, i.e., directly by IR, and indirectly by ISE. The results obtained were 0.299 , $0.296 \mathrm{~mol} / 1$, for IR and ISE, respectively, i.e., both techniques give consistent results.

\section{Conclusions}

Water and electrolyte concentrations in non-derivatizing solvent systems for cellulose can be conveniently and expediently determined by FTIR and ISE. Zwitterionic probes may be employed, provided that the CTC-band is not suppressed by strong probe-electrolyte interactions. Provided that the appropriate ISE is available, the EMF

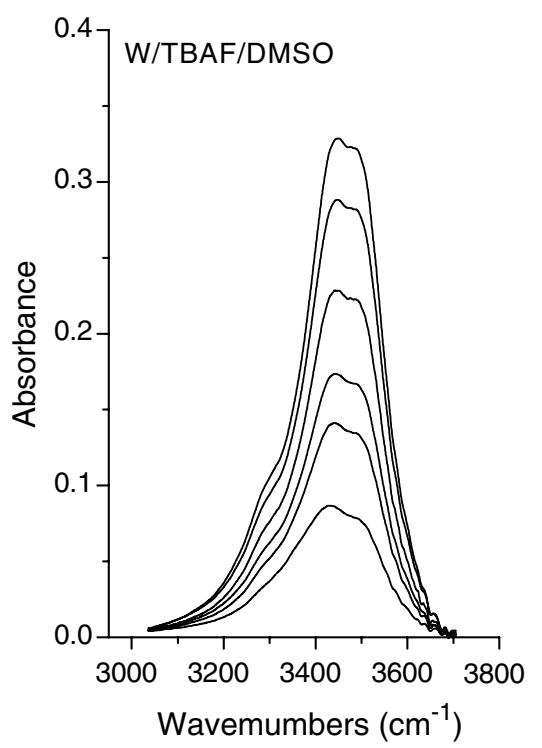

Figure 5. Dependence of peak area on [W] in DMSO and in 2\% TBAF.W/DMSO. The water concentration range was $0.1-0.6 \mathrm{~mol} / 1$, with increments of $0.1 \mathrm{~mol} / 1$. 

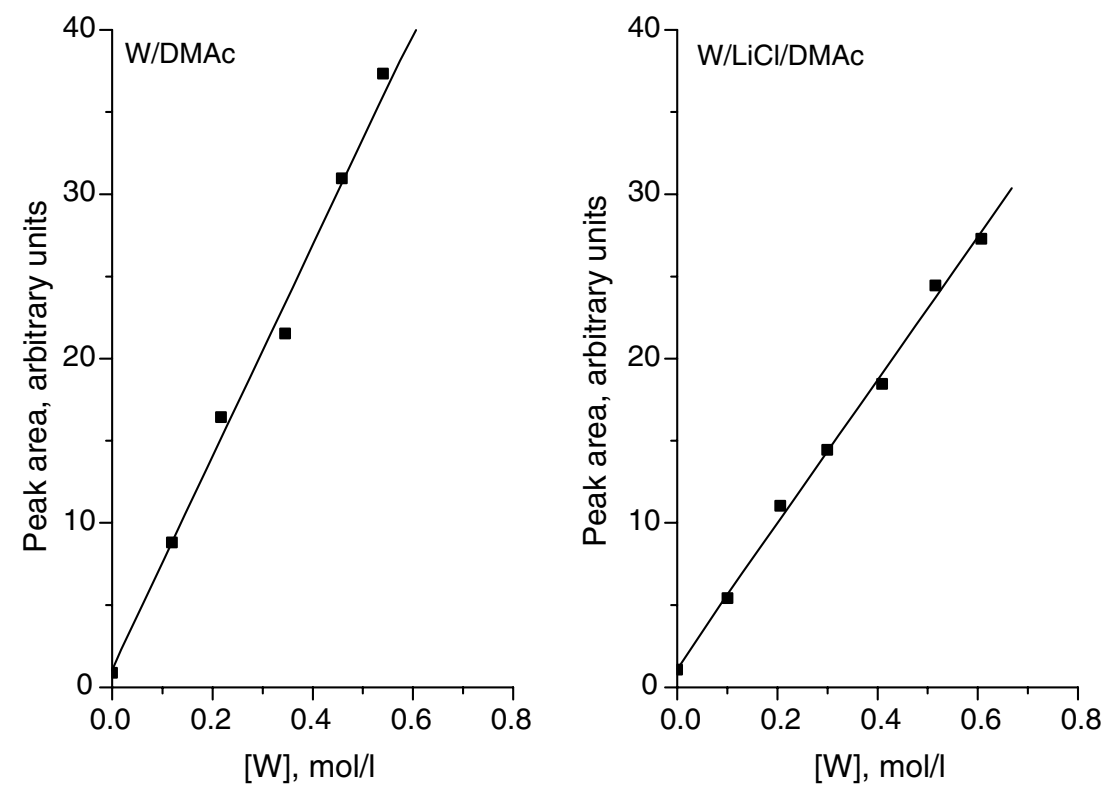

Figure 6. Beer's law plots for the dependence of the areas of $v_{\mathrm{OH}}$ band on [W], in DMAc and $1.0 \mathrm{~mol} / 1 \mathrm{LiCl} / \mathrm{DMAc}$.

method is recommended because it employs simple equipment and software (for regression analysis), maybe employed for anhydrous systems, e.g., $\mathrm{LiCl} / \mathrm{DMAc}$, and requires no prior training of the operator, e.g., in software for manipulation of spectroscopic data.

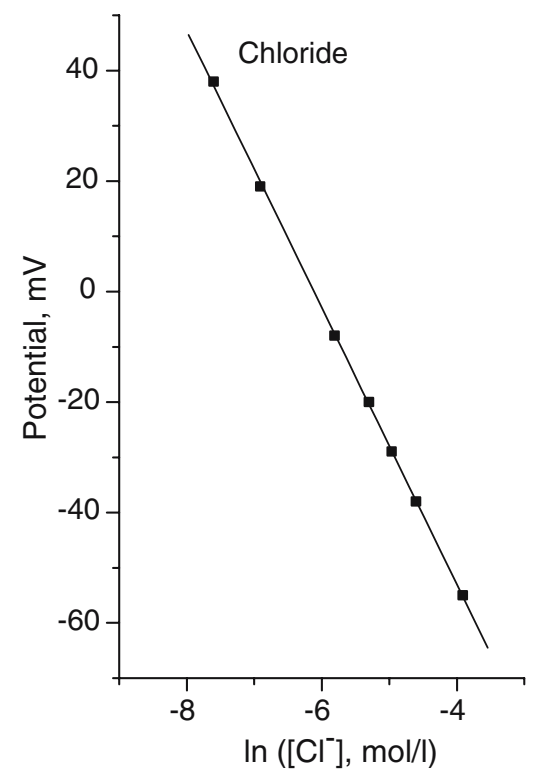

The present results are relevant to cellulose functionalization under homogeneous solution conditions since they permit accurate determination of the solvent system composition. This information rationalizes the energy/labor involved in drying the electrolyte, and optimizes the yield of the derivative

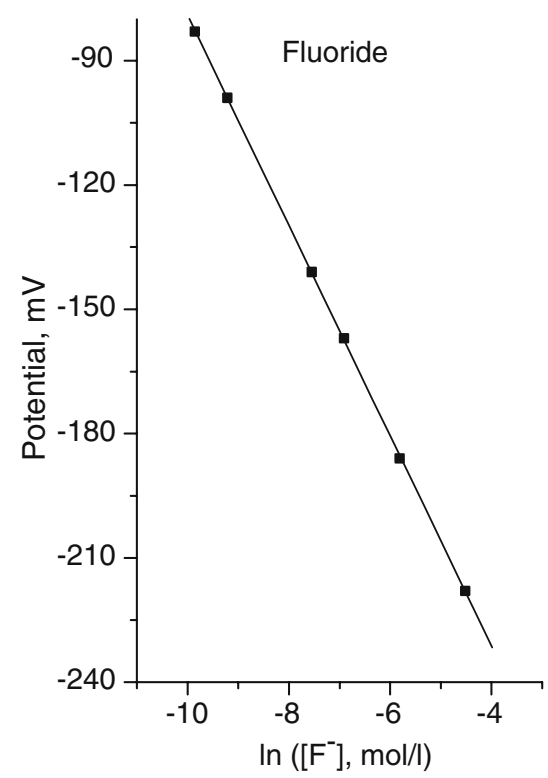

Figure 7. Calibration plots (Nernst equation) for the ISEs employed, using $\mathrm{KCl}$ or $\mathrm{NaF}$ in the presence of $0.5 \mathrm{~mol} / 1 \mathrm{KNO}$ and $0.5 \%$ (v/v) DMAc or DMSO, respectively. 
targeted, because the appropriate amount of the functionalizing reagent can be accurately calculated.

\section{Acknowledgements}

The authors thank the Research Foundation of São Paulo (FAPESP) for financial support and a pre-doctoral fellowship to L.C. Fidale, the Brazilian National Research Council (CNPq) for a research fellowship to O.A. El Seoud, the Deutsche Akademischer Austausch Dienst (DAAD) for a fellowship to M.H.G. Prechtl during his stay in São Paulo, the Werkstoffe aus Nachwachsenden Rohstoffen agency (WNR) for financial support to S. Köhler during her stay in São Paulo, Vanessa R. Marques of the Quality Control Department, Colgate-Palmolive, São Paulo, for making the fluoride SIE available to us, Dr Paulo A.R. Pires and $\mathrm{Mr} \mathrm{C}$. Guizzo for their help.

\section{References}

Abakshin V.A., Krestov G.A. and Eliseeva O.V. 1987. Relationship between the relative solubility of highly associated $1-1$ electrolytes and the dielectric permeability of the solvent. Zh. Obshchei Khim. 57: 1606-1609.

Abe Y. and Mochizuki A. 2003. Hemodialysis membrane prepared from cellulose $/ N$-methylmorpholine- $N$-oxide solution. III: the relationship between the drying condition of the membrane and its permeation behavior. J. Appl. Polym. Sci. 89: $1671-1681$.

Aichert A., De Caro C.A., Huber R. and Walter C.M. 1998. Sample preparation: a key issue in Karl Fischer titration. In: Proceedings of the $3 \mathrm{rd}$ International Symposium on Humidity and Moisture, Teddington UK, $141 \mathrm{p}$.

Armarego W.F.L. and Chai C.L.L. 2003. Purification of Laboratory Chemicals 5 th ed. Elsevier, London.

Ass B.A., Frollini E. and Heinze T. 2004. Studies on the homogeneous acetylation of cellulose in the novel solvent dimethylsulfoxide/tetrabutylammonium fluoride trihydrate. Macromol. Biosci. 4: 1008-1013.

De Caro C.A., Aichert A. and Walter C.A. 2001. Efficient, precise and fast water determination by the Karl Fischer titration. Food Contr. 12: 431-436.

Casey M., Leonard J., Lygo B. and Procter G. 1990. Advanced Practical Organic Chemistry. Chapman \& Hall, New York, pp. 43-73.

Chavan R.B. and Patra A.K. 2004. Development and processing of lyocell. Ind. J. Fibre Textile Res. 29: 483-492.

Coleman P.B. 1993. Practical Sampling Techniques for Infrared Analysis. CRC, Boca Raton, p. 11.

Dawsey T.R. and McCormick C.L. 1990. The lithium chloride/ dimethylacetamide solvent for cellulose: a literature review. J. Macromol. Sci. - Rev. Macromol. Chem. Phys. C30: 405-440.
Diamantoglou M., Brandner A. and Meyer G. 1984. Waterinsoluble fibers from cellulose acetate, cellulose propionate and cellulose butyrate with an extremely high absorption capacity for water and physiological fluids. Ger. offen. (1984), DE 3246417 Al 19840620.

Diamantoglou M. and Vienken J. 1996. Strategies for the development of hemocompatible dialysis membranes. Macrom. Symp. 103: 31-42.

Dunkel R., Hahn M., Borisch K., Neumann B., Ruttinger H.-H. and Tschierske C. 1998. Determination of the water content of amphiphilic liquid crystals by coulometric Karl Fischer titration. Liq. Cryst. 24: 211-213.

Dupont A. 2003. Cellulose in lithium chloride/ $N, N$-dimethylacetamide, optimization of a dissolution method using paper substrates and stability of the solutions. Polymer 44: 4117-4126.

El Seoud O.A., Marson G.A., Ciacco G.T. and Frollini E. 2000. An efficient, one-pot acylation of cellulose under homogeneous reaction conditions. Macromol. Chem. Phys. 201: $882-889$.

El Seoud O.A. and Heinze T. 2005. Organic esters of cellulose: new perspectives for old polymers. Advan. Polym. Sci. Springer-Verlag, Berlin, p. 103-149.

Heinze T., Dicke R., Kull A.H., Klohr E.-A. and Koch W. 1999. Effective preparation of cellulose derivatives in a new simple cellulose solvent. Macromol. Chem. Phys. 201: $627-631$.

Heinze T., Dicke R., Koschella A., Kull A.H., Klohr E.-A. and Koch W. 2000. Effective preparation of cellulose derivatives in a new simple cellulose solvent. Macromol. Chem. Phys. 201: 627-631.

Heinze T. and Liebert T. 2001. Unconventional methods in cellulose functionalization. Prog. Polym. Sci. 26: 1689-1762.

Heinze T., Liebert T., Pfeiffer K. and Hussain M.A. 2003. Unconventional cellulose esters: synthesis, characterization and structure-property relations. Cellulose 10: 283-296.

Heinze T. and Liebert T. 2004. Chemical characteristics of cellulose acetate. Macrom. Symp. 208: 167-237.

Heinze T., Schwikal K. and Barthel S. 2005. Ionic liquids as reaction medium for cellulose functionalization. Macromol. Biosci. 5: 520-525.

Ikeda I., Washino K. and Maeda Y. 2003. Graft polymerization of cyclic compounds on cellulose dissolved in tetrabutylammonium fluoride/dimethylsulfoxide. Sen'i Gakkaishi 59: $110-114$.

James D., David W. and Frost R.L. 1978. Structure of aqueous solutions. Infrared librational band study of structure making and structure breaking by dissolved electrolytes. J. Chem. Soc., Faraday Trans. 174: 583-596.

Kessler M.A. and Wolfbeis O.S. 1989. $E_{\mathrm{T}}(33)$, a solvatochromic polarity and micellar probe for neutral aqueous solutions. Chem. Phys. Lipids 50: 51-56.

Lacey R.E. 1997. Dialysis and Electrodialysis. Handbook of Separation Techniques for Chemical Engineers 3rd ed. Wiley, New York, pp. 619-635.

Kolthoff J.M. and Elving P.J. 1971. Treatise on Analytical Chemistry, Vol. 1, Part II, Sect. A. Interscience, New York, p. 69.

Langhals H. 1982. Polarity of binary liquid mixtures. Angew. Chem. Int. Ed. Engl. 21: 724-733.

Levkin A.V. and Tsivadze A.Y. 1986. Solubility of lithium and potassium halides in pyridine, acetonitrile, and $\gamma$-butyrolactone. Zh. Neorganicheskoi Khim. 31: 284-285. 
Lindgren J. and Kersti H. 1993. Theoretical simulation and experimental determination of $\mathrm{OH}$ and $\mathrm{OD}$ stretching bands of isotopically diluted HDO molecules in aqueous electrolyte solutions. J. Phys. Chem. 97: 5254-5259.

Liptak B.G. 1994. Analytical Instrumentation. Chilton Book Company, Pennsylvania, p. 186.

Marcus Y. 1997. Ion Properties. Marcel Dekker, New York, p. 209.

Max J.-J. and Chapados C. 2001. IR spectroscopy of aqueous alkali halide solutions: pure salt-solvated water spectra and hydration numbers. J. Chem. Phys. 115: 2664-2675.

Motojima T., Ikawa S. and Kimura M. 1981. Infrared intensities of ion-water interactions in aqueous electrolyte solutions. J. Quant. Spectrosc. Radiative Transfer 26: 177-185.

Mundy W.C., Gutierrez L. and Spedding F.H. 1973. Raman intensities of the uncoupled hydroxyl-doscillators in liquid water. J. Chem. Phys. 59: 2173-2182.

Mussini T., Covington A.K., Longhi P. and Rondinini S. 1985. Criteria for standardization of $\mathrm{pH}$ measurements in organic solvents and water + organic solvent mixtures of moderate to high permitivities. Pure Appl. Chem. 57: 865-876.

Nakayama H. 1983. Hydrates of organic compounds. VII. The effect of anions on the formation of clathrate hydrates of tetrabutylammonium salts. Bull. Chem. Soc. Jpn. 56: 877880.

Pearson R.G. 1988. Absolute electronegativity and hardness: applications to organic chemistry. J. Org. Chem. 54: $1423-$ 1430.

Potthast A., Rosenau T., Buchner R., Röder T., Ebner G., Bruglachner H., Sixta H. and Kosma P. 2002. The cellulose solvent system $N, N$-dimethylacetamide/lithium chloride revisited: the effect of water on physicochemical properties and chemical stability. Cellulose 9: 41-53.

Ramos L.A., Assaf J.M., El Seoud O.A. and Frollini E. 2005. Influence of the supramolecular structure and physicochemical properties of cellulose on its dissolution in lithium chloride/ $N, N$-dimetylacetamide solvent system. Biomacromology 6: $2638-2647$.

Reichardt C. 2003. Solvents and Solvent Effects in Organic Chemistry 3rd ed. Verlag Chemie, Weinheim, p. 389.

Röder T., Morgenstern B., Schelosky N. and Glatter O. 2001. Solutions of cellulose in $N, N$-dimethylacetamide/lithium chloride studied by light scattering methods. Polymer 42: 6765-6773.

Samaranayake G. and Glasser W. 1993. Cellulose derivatives with low DS. I: a novel acylation system. Carbohyd. Polym. 22: $1-7$.

Scherer J.R. 1980. The vibrational spectroscopy of water. In: Clark R.J. and Hester R.E. (eds), Advanced Infrared Raman Spectroscopy. Wiley, New York, pp. 149-216.

Scholz E. 1984. Karl-Fischer Tritation. Springer-Verlag, Berlin.

Sharma R.K. and Fry J.L. 1983. Instability of anhydrous tetran-alkylammonium fluoride. J. Org. Chem. 48: 2112-2114.

Sipos P., Bódi I., May P.M. and Hefter G.T. 1997. The ionic product of water in concentrated tetramethylammonium chloride solutions. Talanta 44: 617-620.
Sjoholm E., Gustafsson K., Pettersson B. and Colmsjo A. 1997. Characterization of the cellulosic residues from lithium chloride/ $N, N$-dimethylacetamide dissolution of softwood kraft pulp. Carbohydr. Polym. 32: 57-63.

Spear S.K., Holbrey J.D. and Rogers R.D. 2004. Production of bioactive cellulose films reconstituted from ionic liquids. Biomacromology 5: 1379-1384.

Steinmeier H. 2004. Chemistry of cellulose acetylation. Macrom. Symp. 208: 49-60.

Sun H. and DiMagno S.G. 2005. Anhydrous tetrabutylammonium fluoride. J. Am. Chem. Soc. 127: 2050-2051.

Swatloski R.P., Spear S.K., Holbrey J.D. and Rogers R.B. 2002. Dissolution of cellulose with ionic liquids. J. Am. Chem. Soc. 124: 4974-4975.

Tada E.B., Novaki L.P. and El Seoud O.A. 2000. Solvatochromism in pure and binary solvent mixtures: effects of the molecular structure of the zwitterionic probe. J. Phys. Org. Chem. 13: 679-687.

Tada E.B., Silva P.L. and El Seoud O.A. 2003. Thermo-solvatochromism of betaine dyes in aqueous alcohols: explicit consideration of the water-alcohol complex. J. Phys. Org. Chem. 16: 691-699.

Tada E.B. 2004. Use of Solvatochromic Dyes to Study Solvation in Pure Solvents, Their Mixtures, and Micellar Solutions. Ph.D Thesis, University of São Paulo.

Tada E.B., Silva P.L., Tavares C. and El Seoud O.A. 2005. Thermo-solvatochromism of zwitterionic probes in aqueous aliphatic alcohols and in aqueous 2-alkoxyethanols: relevance to the enthalpies of activation of chemical reactions. J. Phys. Org. Chem. 18: 398-407.

Terbojevich M., Cosani A., Camilot M. and Focher B. 1995. Solution studies of cellulose tricarbanilates obtained in homogeneous phase. J. Appl. Polym. Sci. 55: 1663-1671.

Tiddy G.J.T. 1980. Surfactant-water liquid crystal phases. Phys. Rep. 57: 1-46.

Toyoshima I. 1993. Highly advanced utilization and functionalization of cellulose from the aspects of both chemistry and industry. In: Kennedy John F., Phillips Glyn O. and Williams Peter A. (eds), Cellulosics: Chemical, Biochemical and Material Aspects, Ellis Horwoods, New York, pp. $125-$ 134.

Turner M.B., Spear S.K., Holbrey J.D. and Rogers R.D. 2004. Production of bioactive cellulose films reconstituted from ionic liquids. Biomacromol. 5: 1379-1384.

Wiafe-Akenten J. and Bansil R. 1983. Intermolecular coupling in water-D1 solutions. J. Chem. Phys. 78: 7132-7137.

Woodings C.R. 1995. The development of advanced cellulosic fibers. Intern. J. Biol. Macrom. 17: 305-309.

Wu J., Zhang J., Zhang H., He J., Ren Q. and Guo M. 2004 Homogeneous acetylation of cellulose in a new nonic liquid. Biomacromology 5: 266-268.

Wynn D.A., Roth M.M. and Pollard B.D. 1984. The solubility of alkali-metal flourides in non-aqueous solvents with and without crown ethers, as determined by flame emission spectrometry. Talanta 31: 1036-1040. 